Int. J. Dev. Biol. 61: 195-203 (2017)

doi: $10.1387 / \mathrm{ijdb} .160196 \mathrm{ck}$

\title{
Cell fate decisions during neural crest ontogeny
}

\author{
CHAYA KALCHEIM* and DEEPAK KUMAR \\ Department of Medical Neurobiology, Institute of Medical Research Israel-Canada (IMRIC) and The Edmond and Lily Safra \\ Center for Brain Sciences (ELSC), Hebrew University-Hadassah Medical School, Jerusalem, Israel
}

\begin{abstract}
The neural crest (NC) originates in the central nervous system (CNS) primordium. Born as an epithelium, NC progenitors undergo an epithelial-to-mesenchymal transition that generates cellular movement away from the CNS. Mesenchymal NC progenitors then migrate through stereotypic pathways characteristic of various axial levels until homing to distinct primordia where phenotypic differentiation takes place. Being the source of most of the peripheral nervous system, pigment cells and ectomesenchyme, the embryonic NC is considered to be a multipotent population of precursors. In spite of numerous recent studies, an essential and still unsolved question is when during ontogeny do the different lineages segregate from putative homogeneous and multipotent progenitors. Evidence suggests that the premigratory NC still resident in the dorsal neural tube epithelium is composed both of multipotent as well as of fate-restricted precursors, supporting the notion of an early appearance of cellular heterogeneity. Understanding these changing states of commitment is a prerequisite for deciphering molecular mechanisms that regulate fate segregation of the embryonic NC. In this review, we present data illustrating the existence of progenitors harboring different states of specification and their emergence as a function of time and space.
\end{abstract}

KEY WORDS: CNS, PNS, EMT, differentiation, fate-restricted precursor

\section{Introduction}

The neural crest (NC), a transient embryonic population of progenitors leads to a remarkable range of adult derivatives (Groves and Bronner Fraser, 1999, Le Douarin and Kalcheim, 1999). Of particular interest is the finding that the NC not only generates a significant fraction of the peripheral nervous system (PNS) including sensory, sympathetic, parasympathetic and enteric neurons as well as all the peripheral glia including Schwann cells, but also distinct non neural cell types such as melanocytes, endocrine cells and various types of mesenchymal cells that include significant portions of the craniofacial skeleton [(Etchevers et al., 2001, Graham et al., 2004, Le Douarin and Kalcheim, 1999, Noden, 1978), but see (Weston and Thiery, 2015)]. Although different derivative combinations are apparent at the various levels of the embryonic axis, in each region, multiple NC-derived cell types are generated (Kuo and Erickson, 2010, Kuo and Erickson, 2011, Le Douarin, 1982, Le Douarin and Kalcheim, 1999). Classical fate mapping studies of NC populations as well as heterotopic and heterochronic transplantations led years ago to the notion that the premigratory $\mathrm{NC}$ is largely multipotent, but also highlighted specific derivatives that seemingly segregate early on from this multipotent population (Le Douarin, 1990, Le Douarin and Dupin, 2003, Le Lievre et al., 1980, Rothman et al., 1990, Schweizer et al., 1983). This left open the question, discussed in the present review, whether multipotency is also a property inherent to single or to small groups of premigratory progenitors as evidenced by lineage tracing in the embryo at precise stages and locations.

\section{The dynamic behavior of the dorsal neural tube during} the neural crest period: implications for lineage analysis

Vital dye labeling of the dorsal neural tube (NT) revealed that $\mathrm{NC}$ cells migrate in a stereotypic manner leading to a general ventral to dorsal order of colonization of peripheral derivatives. In the trunk of avian and zebrafish embryos, a ventralward migration leads first to colonization of sympathetic ganglia followed by

\footnotetext{
Abbreviations used in this paper: BMP, bone morphogenetic protein; CNS, central nervous system; DRG, dorsal root ganglion; GFP, green fluorescent protein; NG, neural crest; NT, neural tube; NF-M, neurofilament M; RP, roof plate; ss, somite stage; $\mathrm{TH}$, tyrosine hydroxylase.
}

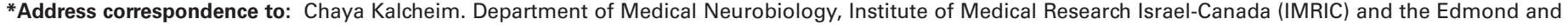
Lily Safra Center for Brain Sciences (ELSC), Hebrew University-Hadassah Medical School, Jerusalem 9112102- P.O.Box 12272, Israel. Fax: \#972-2-675-7451. Tel: \#972-2-675-8438. E-mail: kalcheim@cc.huji.ac.il - web: http://sites.google.com/site/kalcheimlab - http://orcid.org/0000-0002-4612-9438
}

Accepted: 24 June 2016.

ISSN: Online 1696-3547, Print 0214-6282 
the DRG; the last cells to migrate are melanoblasts that follow a subectodermal pathway (Erickson et al., 1992, Raible and Eisen, 1994, Raible et al., 1992, Serbedzija et al., 1989, Weston and Butler, 1966). Also in mouse and Xenopus embryos, both ventral and subectodermal pathways exist yet, in contrast to the precedent species, they seem to be invaded simultaneously (Collazo et al., 1993, Serbedzija et al., 1990).

The ordered events taking place in the periphery, for example the continuous emigration of NC cells for over two days in the trunk of avian embryos, and consequently, ordered colonization of derivatives, raised the question whether this is accounted for by a corresponding organized replenishment of the premigratory pool until the end of NC production, or alternatively, whether localization in, and

A

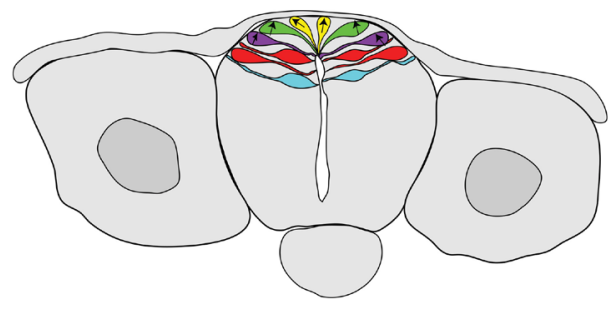

B

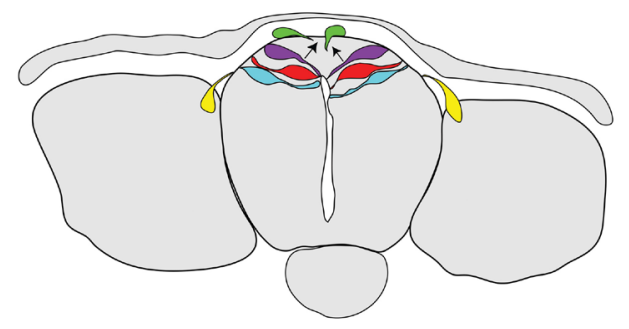

C

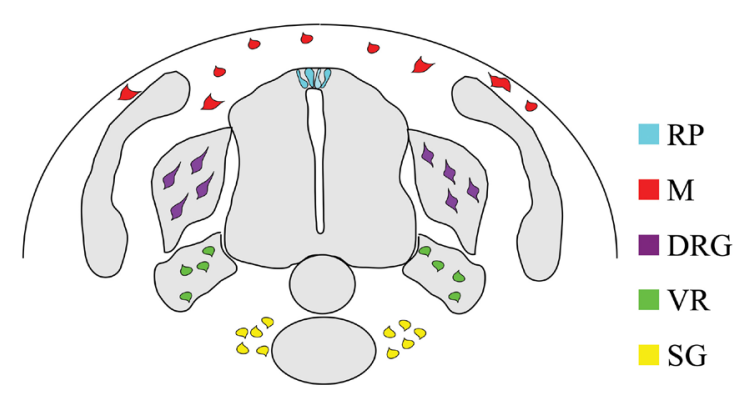

Fig. 1. A dynamic spatiotemporal fate map of neural crest (NC) derivatives. (A) Dorsal neural tube cells prior to emigration; (B) emigrating NC progenitors and within the neural tube, dorsalward cell relocation prior to emigration; (C) the organogenetic stage. Color codings represent relative positions of NC progenitors in the neural tube vis-à-vis their final homing sites. The sequential and stereotypic ventral to dorsal order of colonization of trunk NC derivatives is accounted for by an ordered emigration of presumptive NC progenitors. Furthermore, continuous cell exit is accounted for by a corresponding ventral to dorsal relocation of epithelial progenitors towards the dorsalmost area of the neural tube which therefore acts as a transition zone for the progressive influx and departure of cells. Sequential cell emigration thus causes a progressive narrowing of the pre-migratory NC domain until its disappearance from the dorsal tube and concomitant replacement by the definitive roof plate. Abbreviations; $D R G$, dorsal root ganglion; $M$, melanocytes; $S G$, sympathetic ganglion; $R P$, roof plate; $V R$, ventral root. delamination from the dorsal NT are random processes. To address these questions, small cell populations in the avian dorsal NT at flank regions were lineage traced. Most labeled cells delaminated without leaving residual progeny in the neuroepithelium excluding an asymmetric mode of cell emigration [(Krispin et al., 2010b) and see also (Ahlstrom and Erickson, 2009)]. This process was associated with a corresponding relocation of neuroepithelial progenitors towards the dorsalmost region followed by cell emigration. The precedent phenomenon was coupled to the progressive restriction of expression domains of dorsal NT genes such as FoxD3, Sox9 and Snail2. Altogether, this dynamic sequence of events suggests that initial NC delamination generates the relocation of epithelial progenitors towards the dorsal midline region. Consequently, a progressive narrowing of the pre-migratory NC domain occurs until its exhaustion and concomitant replacement by the definitive RP (Fig. 1). Together, these data suggest that the dorsal midline area of the NT acts as a transition zone for the progressive influx and departure of cells (Fig.1). This ventro-dorsal cellular progression followed by cell delamination in vivo was confirmed in a later study that applied a photoconvertible fluorescent protein and confocal microscopy (McKinney et al., 2013).

These results raised the fundamental question whether there is any relationship between this ordered cellular behavior and the establishment of distinct fates. Labeling of the dorsal midline region of the NT at a precise segmental level of progressively older embryos generated labeled progeny in discrete sites corresponding to the observed sequence of target colonization (Fig. 2). The results of this experimental paradigm were equivalent to those obtained upon labeling of cells located at various dorsoventral domains of the dorsal quarter (25\% approximately) of the NT at a given stage (Krispin et al., 2010b). Hence, a dynamic spatial and temporal map of NC derivatives exists in the premigratory domain of the NT with the final localization and fate of prospective NC cells being predictable from their relative position within the NT at a given stage as well as from their time of emigration.

While confirming the overall ventral to dorsal movement toward the midline of the NT, McKinney et al., argued that NC cells exit in a stochastic manner to populate multiple derivatives (McKinney et al., 2013). No differences were noticed in this study in the ability of precursors from different dorsoventral levels of the NT to contribute to NC derivatives, with the exception of sympathetic ganglia, which, in agreement with Krispin and colleagues (Krispin et al., 2010b) appeared to be 'filled' by the first population to emigrate. Possible reasons for this partial discrepancy are the use by McKinney et al., of embryos exhibiting a wide range of stages even if analysis focused on a given somite level. Since labelings were performed at selected depths in the dorsoventral extent (spatial fate mapping), these categories are likely to contain different progenitor types at the various stages. In addition, initial cellular positions in the dorsal NT were calculated by scaling onto a fixed NT template in spite of age variability. Monitoring in each embryo the relative localization of a labeled cell out of the total dorsoventral extent of the NT (see Krispin et al., 2010b) might provide a better mean to overcome age heterogeneity and keep with the dynamics of the process. Furthermore, complementing these results with a careful temporal map of derivatives upon labeling of a single region, the dorsal midline of the NT, would have been warranted to better compare the data of McKinney and colleagues with those of Krispin et al., .

From the dynamic fate map established by Krispin et al., (2010b), 
it follows that a specific somitic level of the NT yields different fates at different ages (Fig. 2). This raised the question whether premigratory NC progenitors are early fate restricted cells, or whether the discrete fates observed in the lineage analysis are imposed on multipotent premigratory cells by the environment following cell exit. To address this question, prospective neural progenitors were diverted into the melanocytic pathway. In spite of this change in migratory path, the labeled cells still adopted neural traits, in support of the existence of environment-independent fate restrictions among neural precursors. Nevertheless, these data do not necessarily imply that cells are fully specified prior to emigration. In fact, upon ganglion colonization, some labeled cells generated both neurons and glia (Krispin et al., 2010b), consistent with the notion that neuron-glia segregation is a late decision that takes place in the ganglionic environment (Wakamatsu et al., 2000).

Together, these results provided for the first time a link between the topography of premigratory progenitors, cell delamination and acquisition of specific fates (Krispin et al., 2010a, Krispin et al., 2010b). The notion that particular premigratory NC cells are fate-restricted does not rule out the existence of multipotent progenitors (see below, section on Schwann cell progenitors) or of plasticity of restricted progenitors, as evidenced in back grafting experiments [reviewed in (Le Douarin and Kalcheim, 1999)]. In the latter, however, chimeras were analyzed only late in development; under these conditions restricted/specified progenitors might not have survived in ectopic locations.

\section{Neural and melanocyte lineages separate prior to cell delamination from the neural tube}

In ovo lineage analysis of the dorsal NT was performed opposite somitic level 23 at progressively older stages. This analysis, which encompassed labeling with DNA-GFP of 1-3 progenitors/embryo revealed that when transfections were performed in 15-25 somite stage (ss) embryos, $72 \%$ of the progeny localized to sympathetic ganglia and only 12 and $16 \%$ in ventral roots and DRG, respectively. By 28-29ss no colonization of sympathetic ganglia was observed any longer and instead in $22 \%$ of cases labeling was detected along ventral roots and in $78 \%$ in DRG. Injections between $30-31 \mathrm{ss}$, led to labeled progeny restricted to DRG whose colonization spanned a relatively long time period. DRG colonization was over by 35 ss and melanocytes were detected from 32ss until 40ss. The contribution to the definitive RP became apparent from 37ss onward and embryos older than 40ss revealed the presence of labeled progeny only in this structure [(Krispin et al., 2010b) and see Fig. 2]. One inference from this study is that neural and melanogenic fates are temporally segregated, yet the underlying mechanisms remained unknown. Whereas premigratory neural progenitors express FoxD3, Sox9 and Snail2, presumptive melanocytes do not. The question remained open when do prospective melanocytes stop expressing these transcription factors. Analysis of progenitors expressing a specific Foxd3 reporter, confirmed that prospective melanoblasts downregulate Foxd3 and segregate from neural lineages already before emigration. Moreover, when the normal downregulation of Foxd3 is prevented by gene missexpression at a late stage corresponding to the end of neural production, the late-emigrating precursors failed to upregulate the melanogenic markers Mitf
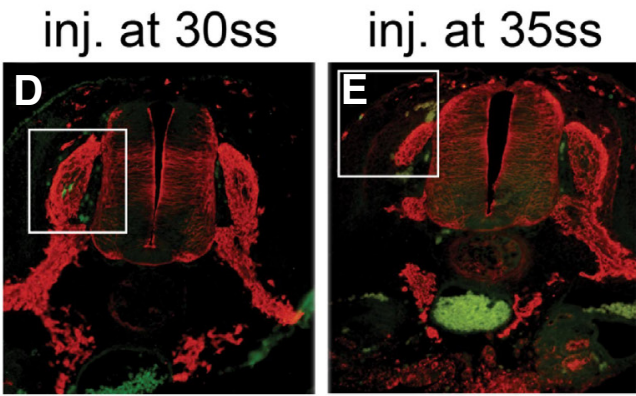

inj. at 40 ss
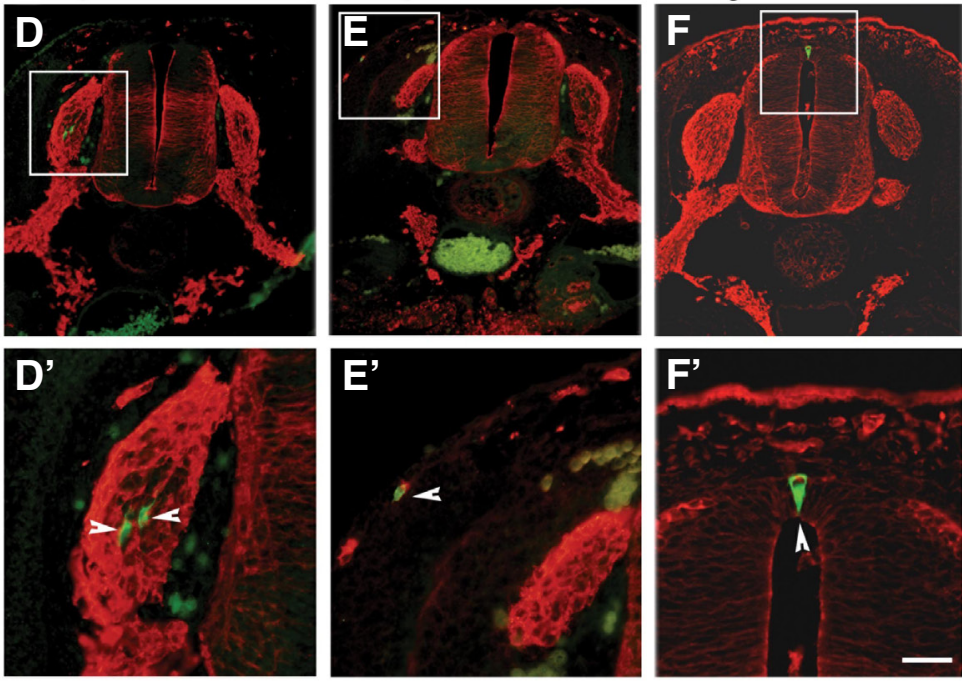

Fig. 2. A temporal fate map of neural crest derivatives in the dorsal neural tube. (A) Transverse section showing discrete labeling of the dorsal neural tube 6hr after microinjection of the PCAGGS plasmid encoding green fluorescent protein (GFP). pCAGGS-GFP injections were performed to the dorsal neural tube opposite the 23rd somite at the stages depicted in each panel, and embryos were fixed at E4.5. (B-F) Transverse serial section analysis of individual embryos reveals that when discretely labeled and at precise stages, dorsal NT cells generate progeny that colonizes single derivatives. Note as well the ordered ventral to dorsal pattern of colonization observed in embryos labeled at increasing stages. (B'-F') Higher magnifications of the insets in (B-F). Sections were counterstained either with Hoechst or with HNK-1. Abbreviations; Ao, aorta; DRG, dorsal root ganglion; $M$, melanocytes; $N T$, neural tube; $S G$, sympathetic ganglion; $R P$, roof plate; $V R$, ventral root. Bar, (A), $20 \mu \mathrm{M}$; $(B-F), 100 \mu \mathrm{M}$; $\left(B^{\prime}-F^{\prime}\right), 25 \mu \mathrm{M}$. 
and MC-1 and the guidance receptor Ednrb2, generating instead glial cells that expressed P0 and Fabp (Nitzan et al., 2013a). In this context, Foxd3 was found to operate downstream of Snail2 and Sox9 constituting a minimal network upstream of Mitf and Ednrb2 to link melanogenic specification with migration. In a reciprocal experiment, loss of Foxd3 function in mouse NC resulted in ectopic melanogenesis in the dorsal tube, in sensory ganglia and along ventral roots (Nitzan et al., 2013a, Nitzan et al., 2013b). These results suggest that a timely downregulation of FoxD3 gene activity in the dorsal NT is necessary for the switch between neural and melanocytic phases of NC development. In this regard, a previous study also highlighted the need for downregulating Foxd3 to enable upregulation of Mitf and melanogenesis, albeit in this study Foxd3 was missexpressed at very early stages thus comprising both neural as well as melanogenic precursors rather than attaining exclusively the presumptive pigment cell subset (Thomas and Erickson, 2009). Hence, it remained unclear whether the responsive cells consisted of neural precursors, melanocyte progenitors, or both subsets. Since similar to the downregulation of Foxd3, also

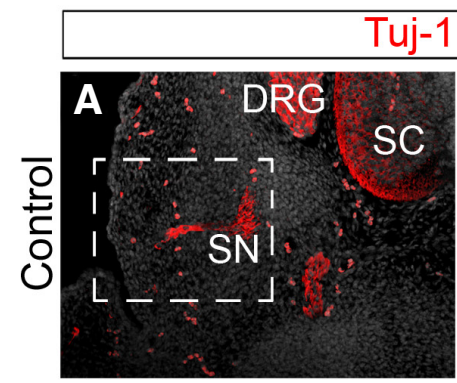

\section{Mitf}
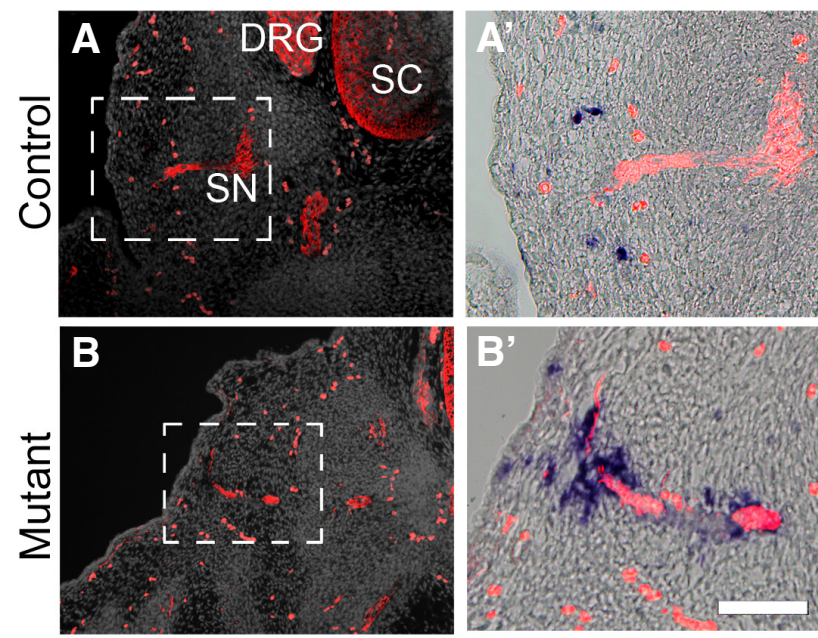

C

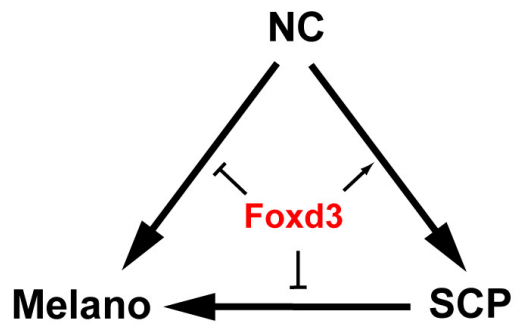

Fig. 3. Foxd3 inhibits melanogenesis in neural crest precursors. Enhanced melanogenesis in mutant mouse embryos carrying a conditional deletion of Foxd3 in the NC. Foxd3 $3^{\text {flox-}}$; Wnt1-Cre; R26R (mutant) embryos were compared to Foxd $3^{\text {floxt+ }}$; Wht1-Cre; R26R (control) embryos. (A-B') Staining for Mitf and Tuj-1 in sections through spinal nerves of 12.5 days post-coitum $(\mathrm{dpc})$ control and mutant mouse embryos. Note ectopic Mitf+ cells closely associated to the nerves in mutant mice. (C) Model summarizing the role of Foxd3 in melanocytes emanating either directly from the NC or indirectly from NC-derived Schwann cell progenitors. Foxd3 stimulates the Schwann cell fate while inhibiting melanogenesis. Abbreviations; DRG, dorsal root ganglion; SC, spinal cord; SCP, Schwann cell precursors; SN, spinal nerve. Bar, $50 \mu \mathrm{m}$.
Snail2 and Sox9 are lost from the dorsal NT prior to melanoblast emigration, it is likely that the latter two, along with Foxd3, form part of a network that influences neural vs. melanocyte development, respectively. The differential expression of these three genes to prospective neural lineages but not to melanoblasts, highlights early molecular differences between the above fates apparent already in the premigratory domain. Consistent with this molecular heterogeneity, previous studies demonstrated that progenitors expressing the neurotrophin receptor TrkC generated neural derivatives only whereas c-kit+ cells produced only melanocytes (Luo et al., 2003).

\section{Schwann cell progenitors, a source of multiple lineages}

Myelinating and non-myelinating Schwann cells derive from early dorsoventrally emigrating NC progenitors and then associate with and migrate along peripheral axons (Jessen and Mirsky, 1997, Jessen and Mirsky, 1999). Two landmark lineage analyses reported that Schwann cell progenitors in both the trunk and the head are also the source of many skin melanocytes in addition to those emanating directly from the dorsal NT (Adameyko et al., 2009, Adameyko et al., 2012). This discovery is consistent with results of in vitro clonal analysis that revealed the existence of single NC cells with melanocyte-glial potential (Dupin et al., 2003, Dupin and Le Douarin, 2003), and on the other hand, with various skin diseases which show an intimate connection between Schwann and pigment cells (Adameyko and Lallemend, 2010).

Schwann cell precursors in the trunk were found to express Sox10 and Krox20 and to constitute the major cell type apparent along tight nerve bundles; however, in the distal defasciculating regions of nerves, melanocytes became apparent. Thus, the fate of Schwann cell progenitors as Schwann or pigment cells seems to be linked to the strength of cellular contact with nerve fibers. Interactions with Neuregulins and their ErbB3 receptor were documented to be necessary for Schwann cells to be produced whereas insulin-like growth factor 1 and platelet-derived growth factor seem to be required for melanocyte development, at least in vitro (Adameyko et al., 2009). Likewise, a large center of head melanocytes in and around cranial nerves IX-X was reported to derive from Schwann cell progenitors, as shown by genetic celllineage tracing and analysis of ErbB3-null mutant mice. In contrast, other cranial melanocytes were shown to arise independently of nerves (Adameyko et al., 2012).

Therefore, skin melanocytes arise from two sources, either directly from NC progenitors or indirectly, from NC-derived Schwann cell precursors following colonization of peripheral nerves, and regional differences are apparent (Table 1). Except for their common origin in the NC, the relationship between these two melanocyte populations and the factors controlling their specification remain poorly understood. Specific lineage tracing of late-emigrating NC progenitors which directly generate melanocytes or of earlyemigrating, nerve-associated Schwann cells revealed that the resulting melanocytes are differentially constrained to the epaxial and hypaxial body domains, respectively. Furthermore, while both populations are initially part of the Foxd3 lineage, hypaxial melanocytes lose Foxd3 at late stages upon separation from the nerve (Nitzan et al., 2013b) whereas epaxial melanocytes segregate from Foxd3-positive neural progenitors at an earlier stage when still residing in the dorsal NT (Nitzan et al., 2013a) (Table 1). Gain and loss of function experiments in avians and mice, respectively, 
TABLE 1

\section{TWO NEURAL CREST-DERIVED SOURCES OF BODY MELANOCYTES}

\begin{tabular}{|c|c|c|c|}
\hline $\begin{array}{l}\text { Time of } \\
\text { emigration }\end{array}$ & Migratory pathway & $\begin{array}{l}\text { Molecular profile } \\
\text { in dorsal NT }\end{array}$ & Fate \\
\hline $\begin{array}{l}\text { Early } \\
\text { emigrating NC }\end{array}$ & Dorso-ventral & $\begin{array}{l}\text { foxd3+ } \\
\text { sox9+ } \\
\text { snail2+ }\end{array}$ & $\begin{array}{l}\text { Schwann cell progenitors that } \\
\text { generate hypaxial melanocytes } \\
\text { and Schwann cells }\end{array}$ \\
\hline $\begin{array}{l}\text { Late } \\
\text { emigrating NC }\end{array}$ & Lateral/subectodermal & $\begin{array}{l}\text { foxd3- } \\
\text { sox9- } \\
\text { snail2- }\end{array}$ & $\begin{array}{l}\text { Direct generation of epaxial } \\
\text { melanocytes }\end{array}$ \\
\hline
\end{tabular}

revealed that Foxd3 is both sufficient and necessary for regulating the balance between melanocyte and Schwann cell development [(Nitzan etal., 2013b) and Fig. 3]. Taken together, body melanocytes originate from two distinct progenitor subsets endowed with different degrees of commitment; epaxial pigment cells are fate-restricted vis-à-vis neural progenitors of the NC, and hypaxial melanocytes arise from, at least, a bi-fated progenitor (Table 1).

Notably, in the head, Schwann cell progenitors appear to exhibit even broader fates. Two laboratories independently discovered that neurons in parasympathetic ganglia are generated entirely from Schwann cell precursors lining peripheral nerves rather than directly from migrating NC. On their way to differentiation, these progenitors transiently display a mixed Schwann cell/autonomic neuron progenitor identity (Dyachuk et al., 2014, Espinosa-Medina et al., 2014). These findings suggest a novel principle of circuit formation by which early neuron/glia progenitors that accompany the presynaptic axons produce postsynaptic neurons.

These results extend previous findings showing that Schwann cell precursors also generate skin melanocytes (see above) that are restricted to the hypaxial body regions (Nitzan et al., 2013b) and also endoneurial fibroblasts (Joseph et al., 2004). Together, this suggests that early developing nerves represent are a source and a pathway to deliver progenitor cells to distant sites. These findings raise major questions. For example, what are the signals that control the Schwann cell progenitor-neuronal switch?, what are the factors eliciting detachment from the nerve and subsequent melanocyte or parasympathetic neuronal differentiation?, is the nerve fiber bundle a niche to maintain cells in a multipotent state? In other words, do individual Schwann cell progenitors display stem cell properties to generate Schwann cells, parasympathetic neurons, melanocytes and endoneural fibroblasts?. Alternatively, are Schwann cell progenitors a population containing fate-restricted subsets endowed with the capacity to produce different fates or fate combinations depending on the spatiotemporal context?. These essential questions, of significance to both basic science and clinical applications, await further investigation.

\section{The segregation between sympathetic neurons and chromaffin cells}

Chromaffin cells originate from the $\mathrm{NC}$ at the level of somites 18-24 and were classically believed to share a common ancestor with sympathetic neurons, leading to the term sympathoadrenal lineage [see below and (Le Douarin and Kalcheim, 1999)]. Following delamination, NC cells of the sympathoadrenal lineage migrate along the ventral migratory route, traversing intersomitic spaces and later, after dissociation of the somites, between dermomyotome and sclerotome and through the rostral sclerotomal mesenchyme (Huber etal., 2009). Following extensive longitudinal migration along the wall of the dorsal aorta, primary sympathetic ganglia coalesce at para-aortic locations from which presumptive chromaffin precursors migrate further ventrally (Unsicker et al., 2005, Vogel and Weston, 1990). Notably, migration of the latter might not be complete as sympathetic ganglia contain about $25 \%$ of chromaffin cells (Huber et al., 2009).

At para-aortic sites, BMPs 2/4/7 derived from the wall of the dorsal aorta and surrounding mesenchyme, induce in these cells a catecholaminergic phenotype, comprising tyrosine hydroxylase (TH) and dopamine $\beta$ hydroxylase (Huber et al., 2009, Reissmann et al., 1996, Schneider et al., 1999). BMP4 is also persistently produced by adrenal cortical cells suggesting it may also affect chromaffin cell development. To examine this possibility, BMP was locally applied to sympathetic ganglia. While the number and sizes of chromaffin granules were significantly increased, the proportion of chromaffin cells normally present in the ganglia remained, however, unchanged (Huber et al., 2008). Thus, BMPs affect selected processes in both sublineages yet high and persistent levels are not sufficient to switch fates between sympathetic neurons and chromaffin cells.

The notion that both lineages stem from common progenitors originates in classical in vitro studies in which manipulating levels of glucocorticoids or of nerve growth factor was able to switch between the two phenotypes (Anderson, 1993, Unsicker et al., 1978). However, analysis of the glucocorticoid receptor knockout mouse revealed that adrenal chromaffin cells developed correctly despite the lack of glucocorticoid signaling (Finotto et al., 1999). In addition, it was shown that chick sympathoadrenal progenitors are already heterogeneous in terms of neurofilament-M (NF-M) expression prior to populating the adrenal gland and sympathetic ganglia (Ernsberger et al., 2005) with presumptive neuronal cells co-expressing $\mathrm{TH}$ and NF-M, and presumptive neuroendocrine cells being $\mathrm{TH}$-positive and NF-M-negative. The above results challenged the sympathoadrenal concept and indicated instead that specification of the respective phenotypes might occur either during migration or even prior to migration at the level of the NT.

Hence, performing an in vivo clonal analysis became important to directly address the question whether the two sublineages were already segregated at the level of the premigratory NC. Single cell electroporations of GFP-DNA were directed to pre-migratory $\mathrm{NC}$ cells of chick embryos at the adrenomedullary level (somites 18-24). The timing and location of transfections was directed to label the earliest progenitors that undergo delamination, previously shown to generate the sympathetic lineage (Krispin et al., 2010b, McKinney et al., 2013), and the progeny of labeled cells was then analysed at E6 following homing to their target areas. In more than $80 \%$ of the cases the progeny of a single labeled cell generated both sympathetic ganglia and adrenomedullary cells, being mostly NF-M-negative in the adrenal gland and NF-M-positive in sympathetic ganglia. In the remaining $20 \%$, clones were found in only one of the two targets (Shtukmaster et al., 2013). Thus, a significant proportion of chromaffin cells and sympathetic neurons share a common progenitor in the NT, yet in considering the molecular heterogeneity detected in NF-M expression, it is likely to assume that phenotype diversification occurs during migration or assembly into primary sympathetic ganglia at the dorsal aorta (Fig. 4). Elucidating the molecular mechanisms responsible for separation of sympathoblasts from chromaffin progenitors remains 
a challenge for future studies.

It is worth emphasizing that, in all cases in which labeled progeny was detected in sympathoadrenal derivatives, no additional NC derivatives (DRG, Schwann cells or melanocytes) were found to contain labeled cells (Fig. 4). This confirms the existence of early fate restrictions as initially described by Krispin et al., (2010b) and more specifically, it further supports the notion that sympathoadrenal progenitors become precociously segregated from the other neural derivatives of the NC (Shtukmaster et al., 2013).

\section{Multipotency versus fate restriction of single neural crest cells}

Since accurate spatiotemporal analysis of small cell groups (1-3 cells/embryo) revealed the existence of fate restrictions among premigratory NC cells, it seems reasonable to assume that this is also the case for single cells (see precedent section).

Consistent with this notion, labeling of single premigratory cells in zebrafish embryos with vital lineage tracers revealed that most zebrafish NC cells in both trunk and head are lineage-restricted, generating type-restricted precursors that produce single kinds of derivatives. Furthermore, in the trunk, some cells produced multiple phenotypes yet they did so by first generating type-restricted precursors, altogether suggesting that NC cells are specified before reaching their final locations (Raible and Eisen, 1994, Raible and Eisen, 1996, Schilling and Kimmel, 1994).

At variance with the zebrafish data, clonal studies performed in chick embryos reached the conclusion that premigratory NC cells

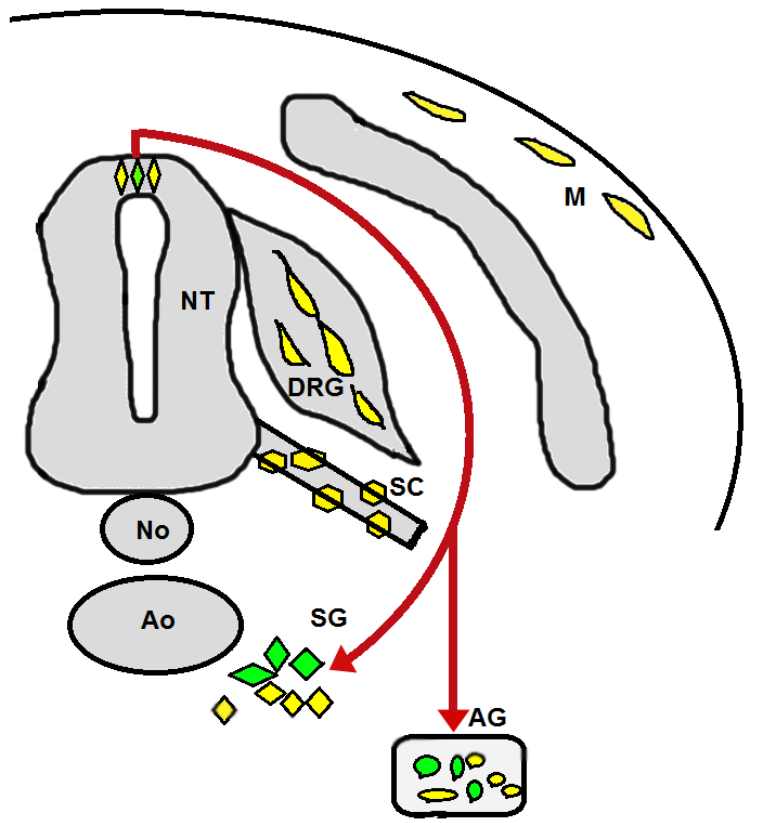

Fig. 4. Early emigrating neural crest progenitors are restricted to the sympathoadrenal lineage. A single dorsal midline progenitor was labeled with a pCAGGS plasmid encoding green fluorescent protein (GFP) at an early delamination stage (see text). Labeled descendants (green cells in scheme) were detected 4 days later in both the sympathetic ganglia (SG) as well as in the adrenal gland (AG). However, no labeled progeny was apparent in either dorsal root ganglia (DRG), as melanocytes (M) or as Schwann cells along peripheral nerves (SC). Abbreviations; DA, dorsal aorta; NT, neural tube; No, notochord. are largely multipotent (Bronner-Fraser and Fraser, 1988, BronnerFraser and Fraser, 1991). One of the studies was based on the finding that in 20 out of 34 embryos $(60 \%)$ labeled cells were found in multiple PNS derivatives. However, in 7 out of these cases, cells were confined to sensory ganglia. In the remaining 14 embryos (40\%) labeled progeny was found only in the NT (Bronner-Fraser and Fraser, 1988). These data might be better compatible with an interpretation suggesting that premigratory NC cells are a mixture of multipotent and restricted progenitors.

This important study was the first to apply clonal methods to analyze the fate of premigratory NC cells in vivo; as such it was limited due to the technical challenges of intracellular injection of living embryos and the small number of differentiation markers available at that time (Bronner, 2015). In addition, although somitic levels 14-24 were chosen to monitor trunk derivatives, embryos of a wide range of ages (from 6-24 somite pairs) were labeled, leaving undefined the precise stages used for the trunk study and the exact dorsoventral levels of injection vis-à-vis the derivatives obtained in a given embryo. These two parameters were shown in later studies to be critical for proper data interpretation (Krispin et al., 2010b). The age variability in these clonal experiments (Bronner-Fraser and Fraser, 1988) may also indicate that many of the injections labeled primitive neuroectodermal progenitors, in which the segregation between NT and NC, or between the various NC fates, did not take place yet. In such cases, the single cells marked might have extensively proliferated within the neuroepithelium prior to emigration, yielding a combination of fate-restricted cells by the time they began exiting the NT, therefore colonizing multiple sites. According to this notion, it might be reasonable to assume that cases in which a single type of progeny was observed reflects injections performed at later stages.

Recently, Baggiolini and colleagues revised this question in the mouse embryo using the R26R-Confetti model (Baggiolini et al., 2015). The authors labeled NC cells at the premigratory or early migrating stages. This temporal specificity was achieved by using the Wnt1-CreER ${ }^{\top}$ or Sox10-CreER ${ }^{\top}$ transgenic lines, respectively. Analysis of results was performed by counting cells expressing a given color or color combination that were present in a "unit", defined as the dorsoventral extent of a trunk segment spanning the width of a single dorsal root ganglion (DRG). Notably, upon labeling premigratory or migrating progenitors, $25.6 \%$ and $21.3 \%$ of clones were found to contain uni-fated progeny, respectively, whereas the remaining clones generated combinations of derivatives containing between 2 and 4 cell types. Based on these data, the authors concluded that the murine trunk NC is multipotent both at premigratory and migrating stages. A reasonable alternative interpretation is that these results actually highlight a significant heterogeneity in cellular fates.

Although making use of innovative lineage tracing methods, the question arises whether this technique is at all suitable for tracing the lineages of individual NC progenitors. The main concern is that in this method, recombination events take place all along the axis yet a short tissue fragment is chosen for quantification ("unit"). It was demonstrated that in avian embryos, DRG progenitors migrate longitudinally along the dorsolateral extent of the NT for a length of one and a half segments before turning ventrally to colonize a given ganglion so that each DRG is composed of progenitors originating from two sequential somitic levels (Teillet et al., 1987). Furthermore, sympathetic progenitors migrate longitudinally along 
the dorsal aorta three segments rostral and three segments caudal of their segment of origin before coalescing into ganglia, and melanoblasts exhibit a similar rostrocaudal dispersion (Le Douarin and Kalcheim, 1999, Yip, 1986). If this behavior is also operative in the mouse embryo, then the presence of labeled cells in DRG, sympathetic ganglia or melanocytes within a given "unit" does not necessarily reflect their origin from a single founder cell located in the respective segment. In other words, a single cell emanating from a given position along the NT can generate progeny along six consecutive segments or, reciprocally, equally labeled cells (e.g, "putative clones") can in fact derive from different founders located in various segmental levels of the neural primordium. Hence, equally colored cells counted in a given unit are not necessarily clones.

In addition to this main caveat, it is somewhat surprising that both premigratory as well as migrating progenitors exhibit a similar degree of multipotency [see also (Bronner-Fraser and Fraser, 1991)]. Evidence for clonality at early developmental stages remains to be demonstrated, as no quantification of the frequencies and absolute numbers of cells bearing a given color combination was presented for either line before organogenetic stages. Additionally, use of lower concentrations of tamoxifen than those employed in the present study $(7.5 \mu \mathrm{g} / \mathrm{g}, 50 \mu \mathrm{g} / \mathrm{g}$ or $150 \mu \mathrm{g} / \mathrm{g})$ would have been informative for further reducing the chances of multiple recombinations per NT segment. In a recent study dealing with cell lineages in the mouse hair follicle niche, $20 \mu \mathrm{g} / \mathrm{g}$ or as low as $1 \mu \mathrm{g} / \mathrm{g}$ tamoxifen were added as a single injection to induce, respectively, expression of two distinct fluorescent reporters. This revealed that the position of a hair follicle stem cell in the niche predicts its fate (Rompolas et al., 2013). Furthermore, it would have been significant to compare results of the Sox 10 transgenic mice with a late recombination performed in the Wnt1 transgenic line (e.g, late addition of tamoxifen corresponding to the onset of cell migration/Sox10 expression).

Although not directly comparable with in vivo lineage tracing, it is worth mentioning that clonal analysis in vitro, where individual cells are challenged with artificial growth conditions to which they are not normally exposed in the embryo, thus examining cellular potentials rather than actual fates, generated $20-25 \%$ of monopotent clones besides multiple derivatives (Baroffio et al., 1988, Baroffio et al., 1990, Baroffio et al., 1991, Trentin et al., 2004). Other protocols that applied short term clonal analysis of NC cells that sequentially emigrated from explanted neural primordia, highlighted instead the existence of a majority of fate restricted progenitors (Henion and Weston, 1997). Clearly, the immense variability in culture conditions employed in the precedent studies (isolation of single cells on cellular or acellular substrates, marking of single cells in an emigrating cohort, the timing of analysis and markers employed, as well as additional variables), may easily account for the differences obtained.

In contrast to in vitrocloning, it would be expected that fate mapping in the embryo generates more consistent results. However, the longstanding controversy on the question of multipotency vs. fate restrictions is, unfortunately, not clarified yet and awaits the use of very precise in vivo clonal techniques that take in consideration the dynamic properties of this unique cell population. Given this dynamic spatiotemporal nature of NC behavior, the basic question should be when during development and at which location do the different lineages segregate from a common progenitor. To resolve this issue, a systematic clonal analysis at various yet exact stages, axial levels and dorsoventral domains of the NT still awaits to be done.

\section{Conclusions and perspectives}

Even though $\mathrm{NC}$ cells can be maintained as self-renewing stem cells for several generations in vitro (Kerosuo et al., 2015), stemness in vivo is likely to be very transient. Evidence from different species suggest that selected NC progenitors become heterogenous already prior to delamination from the NT (e.g, neural vs. epaxial melanocytes in avians, sensory restricted progenitors and melanocytes in zebrafish, etc). Other progenitors still display the capacity to differentiate into a limited number of derivatives during or following migration (e.g, neurons and glia within DRG, sympathetic neurons and chromaffin cells but not additional phenotypes, Schwann cells and hypaxial melanocytes, etc). Although not necessarily fully committed, in all the cases above, progenitors seem to be fate restricted when compared to a true multipotent stem cell able to generate all the derivatives characteristic of a given axial level. We therefore argue that our understanding of lineage segregation of NC progenitors is still incomplete. The remaining challenge is to determine as precisely as experimentally possible when and where during development do lineage restrictions take place. To faithfully address these questions, clonal experimental paradigms should consider the highly dynamic nature of NC behavior. Once this goal is achieved, the road for searching the molecular mechanisms underlying different fate decisions will be more accurately defined.

\section{Acknowledgements}

We thank all the members of our laboratory who contributed data on which this review article is based. We are grateful to Nitza Kahane for critical reading of the manuscript. This work was supported by a grant from the Israel Science Foundation (\#97/13) to CK. DK is supported by fellowships from the Planning and Budgeting Committee of the Council for Higher Education and from the Edmond and Lily Safra Center for Neurosciences (ELSC).

\section{References}

ADAMEYKO, I. and LALLEMEND, F. (2010). Glial versus melanocyte cell fate choice: Schwann cell precursors as a cellular origin of melanocytes. Cell Mol Life Sci 67: 3037-3055.

ADAMEYKO, I., LALLEMEND, F., AQUINO, J.B., PEREIRA, J.A., TOPILKO, P., MULLER, T., FRITZ, N., BELJAJEVA, A., MOCHII, M., LISTE, I. et al., (2009). Schwann cell precursors from nerve innervation are a cellular origin of melanocytes in skin. Cell 139: 366-379.

ADAMEYKO, I., LALLEMEND, F., FURLAN, A., ZININ, N., ARANDA, S., KITAMBI, S.S., BLANCHART, A., FAVARO, R., NICOLIS, S., LUBKE, M. et al., (2012). Sox2 and Mitf cross-regulatory interactions consolidate progenitor and melanocyte lineages in the cranial neural crest. Development 139: 397-410.

AHLSTROM, J.D. and ERICKSON, C.A. (2009). The neural crest epithelial-mesenchymal transition in 4D: a "tail" of multiple non-obligatory cellular mechanisms. Development 136: 1801-1812.

ANDERSON, D.J. (1993). Cell fate determination in the peripheral nervous system The sympathoadrenal progenitor. J.Neurobiol. 24: 185-198.

BAGGIOLINI, A., VARUM, S., MATEOS, J.M., BETTOSINI, D., JOHN, N., BONALLI, M., ZIEGLER, U., DIMOU, L., CLEVERS, H., FURRER, R. et al., (2015). Premigratory and migratory neural crest cells are multipotent in vivo. Cell Stem Cell 16:314-322.

BAROFFIO, A., DUPIN, E. and LE DOUARIN, N.M. (1988). Clone-forming ability and differentiation potential of migratory neural crest cells. Proc.Natl.Acad.Sci. USA. 85: 5325-5329. 
BAROFFIO, A., DUPIN, E. and LE DOUARIN, N.M. (1990). Cell lineage studies in avian neural crest ontogeny. Adv.Exp.Med.Biol. 265: 53-62.

BAROFFIO, A., DUPIN, E. and LE DOUARIN, N.M. (1991). Common precursors for neural and mesectodermal derivatives in the cephalic neural crest. Development 112: 301-305.

BRONNER, M. (2015). Confetti clarifies controversy: neural crest stem cells are multipotent. Cell Stem Cell 16: 217-218.

BRONNER-FRASER, M. and FRASER, S.E. (1988). Cell lineage analysis reveals multipotency of some avian neural crest cells. Nature 335: 161-164.

BRONNER-FRASER, M. and FRASER, S.E. (1991). Cell lineage analysis of the avian neural crest. Development Suppl 2: 17-22.

COLLAZO, A., BRONNER-FRASER, M. and FRASER, S.E. (1993). Vital dye labelling of Xenopus laevis trunk neural crest reveals multipotency and novel pathways of migration. Development 118: 363-376.

DUPIN, E., REAL, C., GLAVIEUX PARDANAUD, C., VAIGOT, P. and LE DOUARIN N. (2003). Reversal of developmental restrictions in neural crest lineages: transition from Schwann cells to glial-melanocytic precursors in vitro. Proc.Natl.Acad. Sci. USA. 100: 5229-5233.

DUPIN, E. and LE DOUARIN, N.M. (2003). Development of melanocyte precursors from the vertebrate neural crest. Oncogene 22: 3016-3023.

DYACHUK, V., FURLAN, A., SHAHIDI, M.K., GIOVENCO, M., KAUKUA, N., KONSTANTINIDOU, C., PACHNIS, V., MEMIC, F., MARKLUND, U., MULLER, T. et al., (2014). Neurodevelopment. Parasympathetic neurons originate from nerveassociated peripheral glial progenitors. Science 345: 82-87.

ERICKSON, C.A., DUONG, T.D. and TOSNEY, K.W. (1992). Descriptive and experimental analysis of the dispersion of neural crest cells along the dorsolateral path and their entry into ectoderm in the chick embryo. Dev.Biol. 151: 251-272.

ERNSBERGER, U., ESPOSITO, L., PARTIMO, S., HUBER, K., FRANKE, A., BIXBY, J.L., KALCHEIM, C. and UNSICKER, K. (2005). Expression of neuronal markers suggests heterogeneity of chick sympathoadrenal cells prior to invasion of the adrenal anlagen. Cell Tissue Res 319: 1-13.

ESPINOSA-MEDINA, I., OUTIN, E., PICARD, C.A., CHETTOUH, Z., DYMECKI, S., CONSALEZ, G.G., COPPOLA, E. and BRUNET, J.F. (2014). Neurodevelopment. Parasympathetic ganglia derive from Schwann cell precursors. Science 345:87-90.

ETCHEVERS, H.C., VINCENT, C., LE DOUARIN, M. and COULY, G.F. (2001). The cephalic neural crest provides pericytes and smooth muscle cells to all blood vessels of the face and forebrain. Development 128: 1059-1068.

FINOTTO, S., KRIEGLSTEIN, K., SCHOBER, A., DEIMLING, F., LINDNER, K., BRUHL, B., BEIER, K., METZ, J., GARCIA-ARRARAS, J.E., ROIG-LOPEZ, J.L. et al., (1999). Analysis of mice carrying targeted mutations of the glucocorticoid receptor gene argues against an essential role of glucocorticoid signalling for generating adrenal chromaffin cells. Development 126: 2935-2944.

GRAHAM, A., BEGBIE, J. and MCGONNELL, I. (2004). Significance of the cranial neural crest. Dev Dyn 229: 5-13.

GROVES, A. and BRONNER FRASER, M. (1999). Neural crest diversification. Curr. Top.Dev.Biol. 43: 221-258.

HENION, P.D. and WESTON, J.A. (1997). Timing and pattern of cell fate restrictions in the neural crest lineage. Development 124: 4351-4359.

HUBER, K., FRANKE, A., BRUHL, B., KRISPIN, S., ERNSBERGER, U., SCHOBER, A., VON BOHLEN UND HALBACH, O., ROHRER, H., KALCHEIM, C. and UNSICKER, K. (2008). Persistent expression of BMP-4 in embryonic chick adrenal cortical cells and its role in chromaffin cell development. Neural Dev 3: 28.

HUBER, K., KALCHEIM, C. and UNSICKER, K. (2009). The development of the chromaffin cell lineage from the neural crest. Auton Neurosci 151: 10-16.

JESSEN, K.R. and MIRSKY, R. (1997). Embryonic Schwann cell development: the biology of Schwann cell precursors and early Schwann cells. J.Anat. 191:501-505.

JESSEN, K.R. and MIRSKY, R. (1999). Schwann cells and their precursors emerge as major regulators of nerve development. Trends Neurosci. 22: 402-410.

JOSEPH, N.M., MUKOUYAMA, Y.S., MOSHER, J.T., JAEGLE, M., CRONE, S.A., DORMAND, E.L., LEE, K.F., MEIJER, D., ANDERSON, D.J. and MORRISON, S.J. (2004). Neural crest stem cells undergo multilineage differentiation in developing peripheral nerves to generate endoneurial fibroblasts in addition to Schwann cells. Development 131: 5599-5612.

KEROSUO, L., NIE, S., BAJPAI, R. and BRONNER, M.E. (2015). Crestospheres: Long-Term Maintenance of Multipotent, Premigratory Neural Crest Stem Cells.
Stem Cell Reports 5: 499-507.

KRISPIN, S., NITZAN, E. and KALCHEIM, C. (2010a). The dorsal neural tube: a dynamic setting for cell fate decisions. Dev Neurobiol 70: 796-812.

KRISPIN, S., NITZAN, E., KASSEM, Y. and KALCHEIM, C. (2010b). Evidence for a dynamic spatiotemporal fate map and early fate restrictions of premigratory avian neural crest. Development 137: 585-595.

KUO, B.R. and ERICKSON, C.A. (2010). Regional differences in neural crest morphogenesis. Cell Adh Migr 4: 567-585.

KUO, B.R. and ERICKSON, C.A. (2011). Vagal neural crest cell migratory behavior: a transition between the cranial and trunk crest. Dev Dyn 240: 2084-2100.

LE DOUARIN, N.M. (1982). The Neural Crest. Cambridge University Press, New York.

LE DOUARIN, N.M. (1990). Cell lineage segregation during neural crest ontogeny. Ann.NY Acad.Sci. 599: 131-140.

LE DOUARIN, N.M. and DUPIN, E. (2003). Multipotentiality of the neural crest. Curr Opin Genet Dev 13: 529-536.

LE DOUARIN, N.M. and KALCHEIM, C. (1999). The Neural Crest. Cambridge University Press, New York.

LE LIEVRE, C.S., SCHWEIZER, G.G., ZILLER, C.M. and LE DOUARIN, N.M. (1980). Restriction of developmental capabilities in neural crest cell derivatives as tested by in vivo transplantation experiments. Dev.Biol. 77: 362-378.

LUO, R., GAO, J., WEHRLE HALLER, B. and HENION, P. (2003). Molecular identification of distinct neurogenic and melanogenic neural crest sublineages. Development. 130: 321-330.

MCKINNEY, M.C., FUKATSU, K., MORRISON, J., MCLENNAN, R., BRONNER, M.E. and KULESA, P.M. (2013). Evidence for dynamic rearrangements but lack of fate or position restrictions in premigratory avian trunk neural crest. Development 140: 820-830.

NITZAN, E., KRISPIN, S., PFALTZGRAFF, E.R., KLAR, A., LABOSKY, P. and KALCHEIM, C. (2013a). A dynamic code of dorsal neural tube genes regulates the segregation between neurogenic and melanogenic neural crest cells. Development 140: 2269-2279

NITZAN, E., PFALTZGRAFF, E.R., LABOSKY, P.A. and KALCHEIM, C. (2013b) Neural crest and Schwann cell progenitor-derived melanocytes are two spatially segregated populations similarly regulated by Foxd3. Proc Natl Acad Sci USA 110: $12709-12714$

NODEN, D.M. (1978). The control of avian cephalic neural crest cytodifferentiation. I. Skeletal and connective tissues. Dev.Biol. 67: 296-312.

RAIBLE, D.W. and EISEN, J.S. (1994). Restriction of neural crest cell fate in the trunk of the embryonic zebrafish. Development 120: 495-503.

RAIBLE, D.W. and EISEN, J.S. (1996). Regulative interactions in zebrafish neural crest. Development 122: 501-507.

RAIBLE, D.W., WOOD, A., HODSDON, W., HENION, P.D., WESTON, J.A. and EISEN, J.S. (1992). Segregation and early dispersal of neural crest cells in the embryonic zebrafish. Dev.Dyn. 195: 29-42.

REISSMANN, E., ERNSBERGER, U., FRANCIS-WEST, P.H., RUEGER, D., BRICKELL, P.M. and ROHRER, H. (1996). Involvement of bone morphogenetic protein-4 and bone morphogenetic protein-7 in the differentiation of the adrenergic phenotype in developing sympathetic neurons. Development 122: 2079-2088.

ROMPOLAS, P., MESA, K.R. and GRECO, V. (2013). Spatial organization within a niche as a determinant of stem-cell fate. Nature 502: 513-518.

ROTHMAN, T.P., LE DOUARIN, N.M., FONTAINE-PERUS, J.C. and GERSHON, M.D. (1990). Developmental potential of neural crest-derived cells migrating from segments of developing quail bowel back-grafted into younger chick host enbryos. Development 109: 411-423.

SCHILLING, T.F. and KIMMEL, C.B. (1994). Segment and cell type lineage restrictions during pharyngeal arch development in the zebrafish embryo. Development 120: 483-494.

SCHNEIDER, C., WICHT, H., ENDERICH, J., WEGNER, M. and ROHRER, H. (1999). Bone morphogenetic proteins are required in vivo for the generation of sympathetic neurons. Neuron 24: 861-870.

SCHWEIZER, G.G., AYER-LE LIEVRE, C. and LE DOUARIN, N.M. (1983). Restrictions of developmental capabilities in the dorsal root ganglia in the course of development. Cell Differ. 13: 191-200.

SERBEDZIJA, G.N., BRONNER FRASER, M. and FRASER, S.E. (1989). A vital dye analysis of the timing and pathways of avian trunk neural crest cell migration. 
Development. 106: 809-816.

SERBEDZIJA, G.N., FRASER, S.E. and BRONNER-FRASER, M. (1990). Pathways of trunk neural crest cell migration in the mouse embryo as revealed by vital dye labelling. Development 108: 605-612.

SHTUKMASTER, S., SCHIER, M.C., HUBER, K., KRISPIN, S., KALCHEIM, C. and UNSICKER, K. (2013). Sympathetic neurons and chromaffin cells share a common progenitor in the neural crest in vivo. Neural Dev 8: 12.

TEILLET, M.A., KALCHEIM, C. and LE DOUARIN, N.M. (1987). Formation of the dorsal root ganglia in the avian embryo: segmental origin and migratory behavior of neural crest progenitor cells. Dev. Biol. 120: 329-347.

THOMAS, A.J. and ERICKSON, C.A. (2009). FOXD3 regulates the lineage switch between neural crest-derived glial cells and pigment cells by repressing MITF through a non-canonical mechanism. Development 136: 1849-1858.

TRENTIN, A., GLAVIEUX-PARDANAUD, C., LE DOUARIN, N.M. and DUPIN, E. (2004). Self-renewal capacity is a widespread property of various types of neural crest precursor cells. Proc Natl Acad Sci USA 101: 4495-4500.

UNSICKER, K., HUBER, K., SCHUTZ, G. and KALCHEIM, C. (2005). The chromaffin cell and its development. Neurochem Res 30: 921-925.

UNSICKER, K., KRISCH, B., OTTEN, U. and THOENEN, H. (1978). Nerve growth factor-induced fiber outgrowth from isolated rat adrenal chromaffin cells: impairment by glucocorticoids. Proc Natl Acad Sci USA 75: 3498-3502.

VOGEL, K.S. and WESTON, J.A. (1990). The sympathoadrenal lineage in avian embryos. I. Adrenal chromaffin cells lose neuronal traits during embryogenesis. Dev.Biol. 139: 1-12.

WAKAMATSU, Y., MAYNARD, T.M. and WESTON, J.A. (2000). Fate determination of neural crest cells by NOTCH-mediated lateral inhibition and asymmetrical cell division during gangliogenesis. Development 127: 2811-2821.

WESTON, J.A. and BUTLER, S.L. (1966). Temporal factors affecting localization of neural crest cells in the chicken embryo. Dev.Biol. 14: 246-266.

WESTON, J.A. and THIERY, J.P. (2015). Pentimento: Neural Crest and the origin of mesectoderm. Dev Biol 401: 37-61.

YIP, J.W. (1986). Migratory pathways of sympathetic ganglioblasts and other neural crest derivatives in chick embryos. J.Neurosci. 6: 3465-3473. 
Further Related Reading, published previously in the Int. J. Dev. Biol.

Lack of organ specific commitment of vagal neural crest cell derivatives as shown by back-transplantation of GFP chicken tissues Lucy J. Freem, Jean Marie Delalande, Alison M. Campbell, Nikhil Thapar and Alan J. Burns Int. J. Dev. Biol. (2012) 56: 245-254

Matrix metalloproteinase-2 is involved in the migration and network formation of enteric neural crest-derived cells

Richard B. Anderson

Int. J. Dev. Biol. (2010) 54: 63-69

Induction of neural crest cells from mouse embryonic stem cells in a serum-free monolayer culture

Yuko Aihara, Yohei Hayashi, Mitsuhi Hirata, Nobutaka Ariki, Shinsuke Shibata, Narihito Nagoshi, Mio Nakanishi, Kiyoshi Ohnuma, Masaki Warashina, Tatsuo Michiue, Hideho Uchiyama, Hideyuki Okano, Makoto Asashima and Miho Kusuda Furue

Int. J. Dev. Biol. (2010) 54: 1287-1294

Neural crest ontogeny during secondary neurulation: a gene expression pattern study in the chick embryo

Liliana Osório, Marie-Aimée Teillet, Isabel Palmeirim and Martin Catala Int. J. Dev. Biol. (2009) 53: 641-648

Transcriptional regulation by Pax3 and TGFbeta2 signaling: a potential gene regulatory network in neural crest development

Hiromichi Nakazaki, Yueh-Wei Shen, Beth Yun, Anvesh Reddy, Varun Khanna, Barbara ManiaFarnell, Shunsuke Ichi, David G. Mclone, Tadanori Tomita and C. Shekhar K. Mayanil Int. J. Dev. Biol. (2009) 53: 69-79
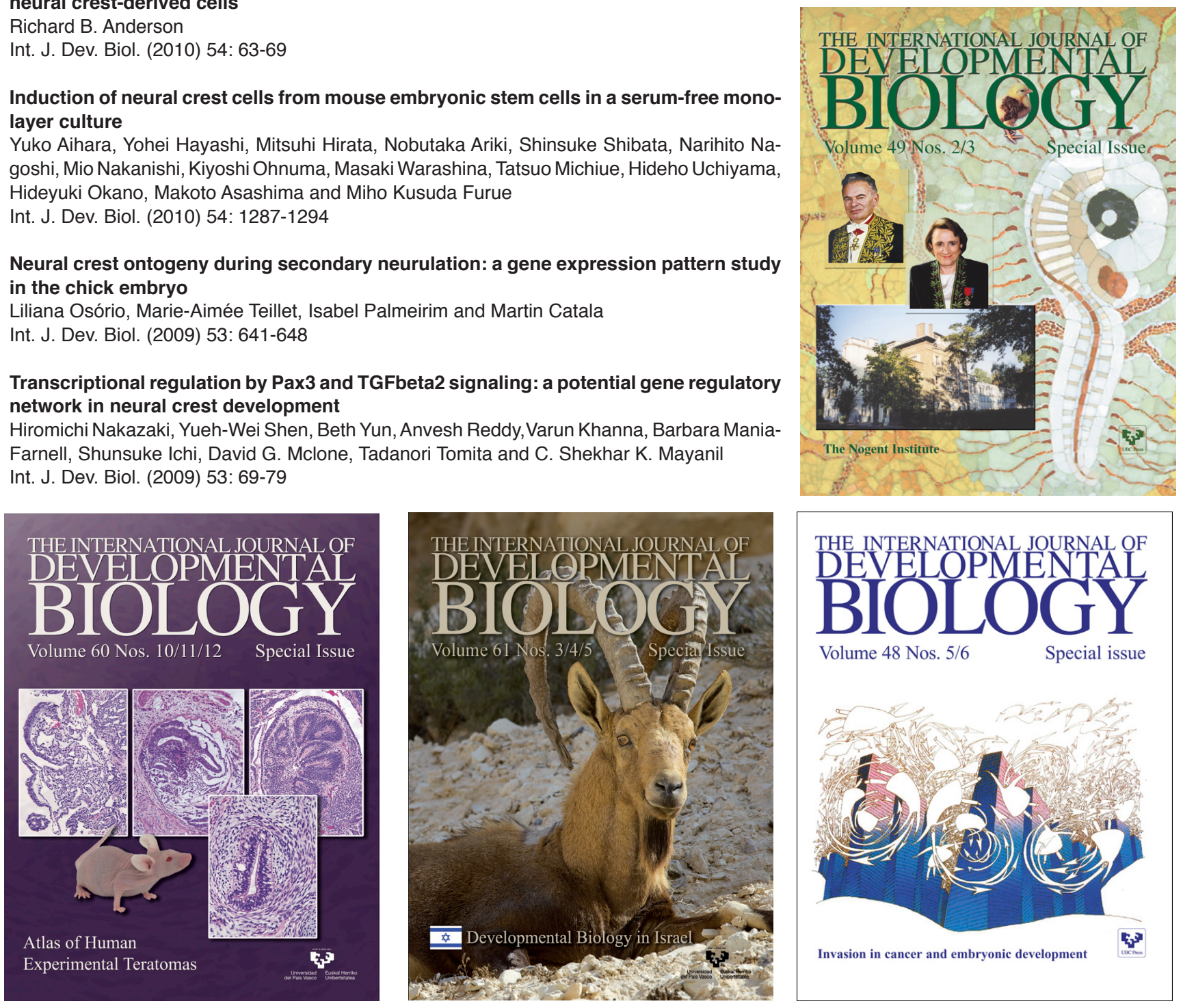

Volume 48 Nos. 5/6

Special issue

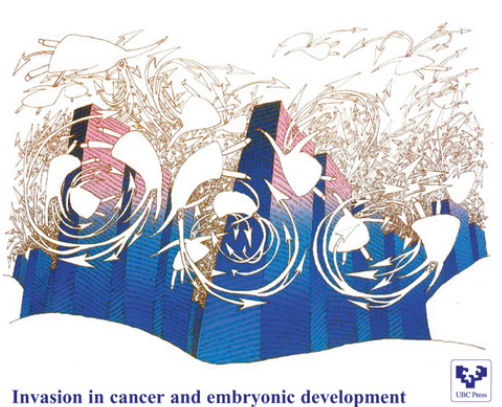

Invasion in cancer and embryonic development 战 